\title{
Theoretical and experimental aspects of saving energy in fans
}

\author{
N. Dizadji • A. M. Mahmoudkhani • \\ N. Nouri
}

Received: 13 June 2011/Revised: 10 November 2011/ Accepted: 2 February 2012/Published online: 8 August 2012

(c) CEERS, IAU 2012

\begin{abstract}
This study presents energy efficiency measures in fans as an important energy consumption facility in the industry and common usages by identifying the sources of energy loss and applying methods to reduce those losses, which are one of the critical issues in protecting the environment and in global warming. The carbon footprint can be lowered by reducing the energy consumption of a fan over its life cycle. The main sources of energy loss in fans such as noise, vibration, lubrication, temperature of the bearings, installation type, damper and filter, especially pulley and belt system compared to electrical variable speed drive, are theoretically and experimentally discussed. The laboratory results show that the mechanical variable speed drive is one of the critical sources of energy loss in centrifugal fans. The results also show that by changing the drive with an electrical variable speed drive, the energy usage can be substantially optimized. For instance, using an electrical variable speed drive has reduced the energy loss up to $38.5 \%$ with regard to the speed and according to the different flow rates. Moreover, based on the results derived from the equations and figures, it can be concluded that a considerable amount of energy per year, as well as the related cost can be saved and this shall be noted particularly in industrial applications.
\end{abstract}

Keywords Energy loss - Energy saving - Fan · Industry $\cdot$ Variable speed drive

\footnotetext{
N. Dizadji $(\bowtie) \cdot$ A. M. Mahmoudkhani · N. Nouri Department of Mechanical Engineering, Science and Research Branch, Islamic Azad University, Tehran, Iran e-mail: ndizadji@srbiau.ac.ir
}

\section{Introduction}

Nowadays, many countries in the world still supply their energy from conventional energy sources and therefore, saving energy is a critical issue to reduce consumption from these types of sources to protect the environment and saving the energy. In addition, energy losses from facilities can cause climate change and finally Global Warming which is the most important problem for the earth and the friends of the environment (Jayamaha 2006). Compressedair systems account for consumption of about $10 \%$ of industrial electricity energy in few countries as found in the literatures (Saidur et al. 2009). Global energy consumption in compressed-air systems is about $400 \mathrm{TWh}$ (Radgen 2006). The compressed-air systems used on mines in South Africa account for approximately $9 \%$ of electricity in the industry (Marais 2009). According to a research in US, over $60 \%$ of the electrical power generated is consumed by fans and pumps, which most of them are of the centrifugal type (Lönnberg 2007). An estimation for use of energy in office buildings in Malaysia showed that about more than a half amount of total electricity power is used by air conditioners (EC 2007) or in other words by electric motors (Leo Building 2005). In the UK, electric motors consume $40 \%$ of total electrical energy that fans are responsible for $22 \%$ consumption of this amount of energy (Andrews et al. 2006). The consumption of electrical power in Iran has increased from 2,220 GWh to approximately 100,000 GWh, between 1976 and 2000 (Massarrat 2004). Therefore, design and production of high efficiency fans to save energy are of great importance for fan manufacturers. Fans transfer static and kinetic energy to the air, creating a pressure difference that causes the air to flow. Fan efficiency is often misunderstood due to the variety of definitions of a fan and what contributes to the losses in a 
fan system (Ragden 2001). The following methods are proposed to reduce the energy loss in fans, in addition to using high efficiency fans:

- Select fan in best efficiency point (BEP) by minimum noise and vibration (Action Energy and Good Practice Guide GPG383 2004)

- Identify factors relating to fan losses (Beggs 2002)

- Consider appropriate grease or oil for fan

- Use filter and change it on time

- Change mechanical drive to electric variable speed drive, VSD (FMA 2006).

In general, various factors cause the energy losses in fans in which the most important of them are discussed as below.

Fan noise

Noise as an important parameter to consider in selecting a fan, is often dominated between $63 \mathrm{~Hz}$ and $10 \mathrm{kHz}$ (AMCA 300 2004). When the matter vibrates, the waves are created in the surrounding medium that has alternating compressions and rarefactions. This represents a small change in the barometric pressure in air that human's eardrums react (Reese et al. 2007). Fan noise represents a characteristic combination of electrical, mechanical and aerodynamic factors (AMCA 202 2004; AMCA 204 2004). It shall be noted that in addition to appropriate fan selection, installation of inlet and outlet channels should be accurately done to reduce the sound level to the minimum level as sound is a source of energy loss (GREENHECK 2008).

Fan vibration

All fans make vibration with a wide frequency range between 3 and $500 \mathrm{~Hz}$. Vibration is due to unbalancing which is the lack of coincidence between center of mass and center of rotation. Excess vibration causes clamps to be separated or fatigue failure of components under load (AMCA 204 2004).

Bearing heat loss

According to the type of fan and its application, oil with appropriate API and ISO viscosity or grease with required NLGI is used as a lubricant that should be replaced every 6 months and during the lifetime they shall be added in the case of leakage or reduction (Dudley 1984). The bearing temperature is normally $80{ }^{\circ} \mathrm{C}$ for the fans which operate in ambient temperature and so, if bearing temperature increases, it shall be replaced or fixed (SKF 1992).
Filter

Filter is an essential component in some types of fans. Dirty or torn filter causes energy loss. In some literature, it has been reported that the energy loss caused by inappropriate filter accounts for more than $40 \%$ of the total energy loss (Tengfang Xu et al. 2006). Although filters reduce the total fan efficiency due to reduction of inlet flow rate, they significantly reduce electricity consumption. Matsuki and Tanaka showed that using a fan system equipped with filter for an area of about $2,000 \mathrm{~m}^{2}$ can reduce electricity consumption by $230 \mathrm{~kW}$ (Matsuki 1998).

\section{Damper}

Damper, as a component of the fan system, controls inlet and outlet air flow rate. The energy consumption of dampers is directly influenced by its type and installation method; inclination and location (MESC 2005). Nowadays, applying controlled vane dampers for variable air volume fan systems can reduce energy consumption by up to $50 \%$ (Belimo Worldwide 2008).

Motor's electrical loss

Nowadays, the most of electrical losses in electrical motors are due to Foucault current on the motor's case or electrical current (Mecrow and Jack 2008). By making layers with insulation material between them for the motor's case and also by selecting and using wires with appropriate diameter and length for the coil, energy losses can be reduced significantly.

Impeller losses

The impeller losses can be classified as hydrodynamic loss, volumetric loss and mechanical loss which are discussed in the literature.

\section{Drive losses}

One of the most important losses in fans is due to the type of drives. These drives are generally belt drives but other mechanical types are available. Figures 1 and 2 illustrate losses from a fan system with direct drive as well as belt drive. Energy loss due to pulley and belt system is determined to be $10-15 \%$ of brake horse power (Bleier 1998).

Variable speed drive as an electrical power converter is used in electric motors to reduce current peaks when starting motors by gradually increasing the motor's speed and also to modulate and control motor's speed, torque and mechanical power output (Rockwell Automation 2007). It has been shown that using VSDs is mostly the 
Fig. 1 The losses from a fan system including motor and belt drive

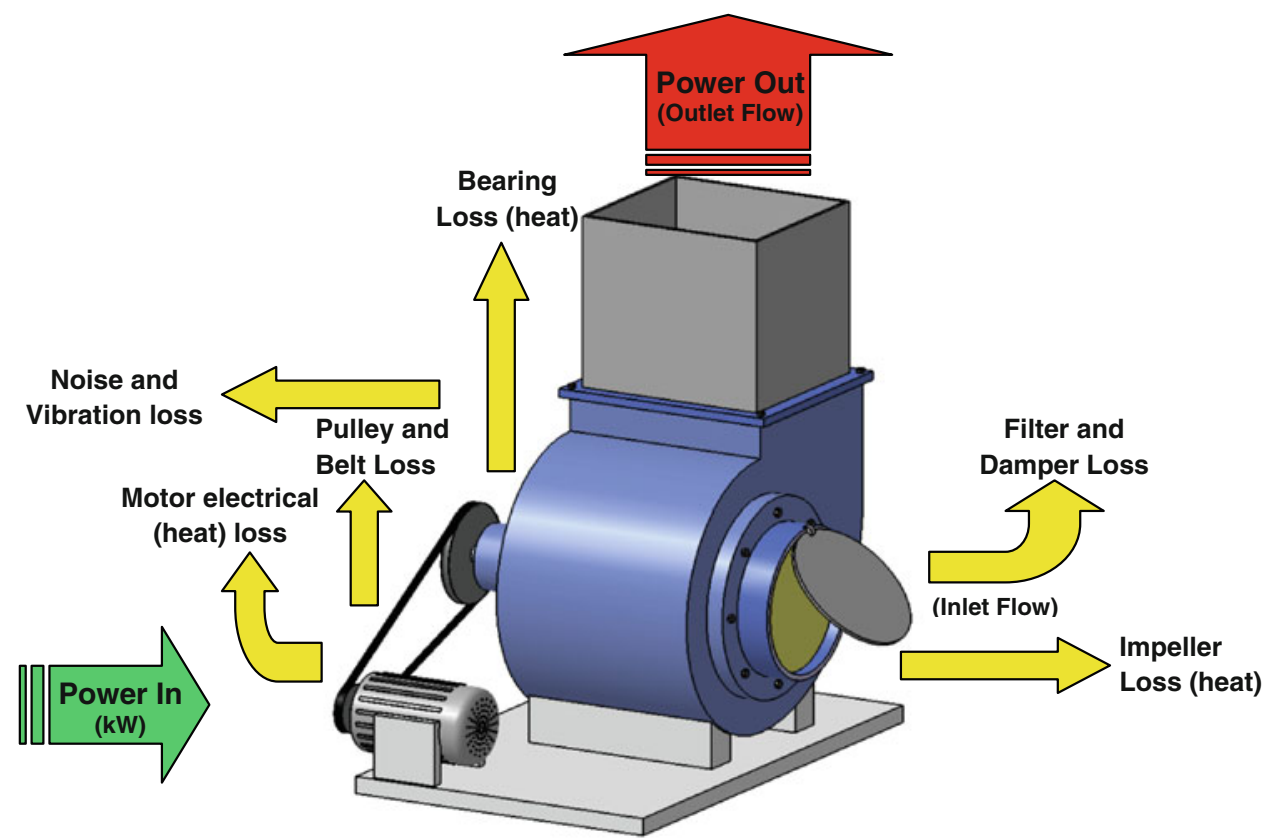

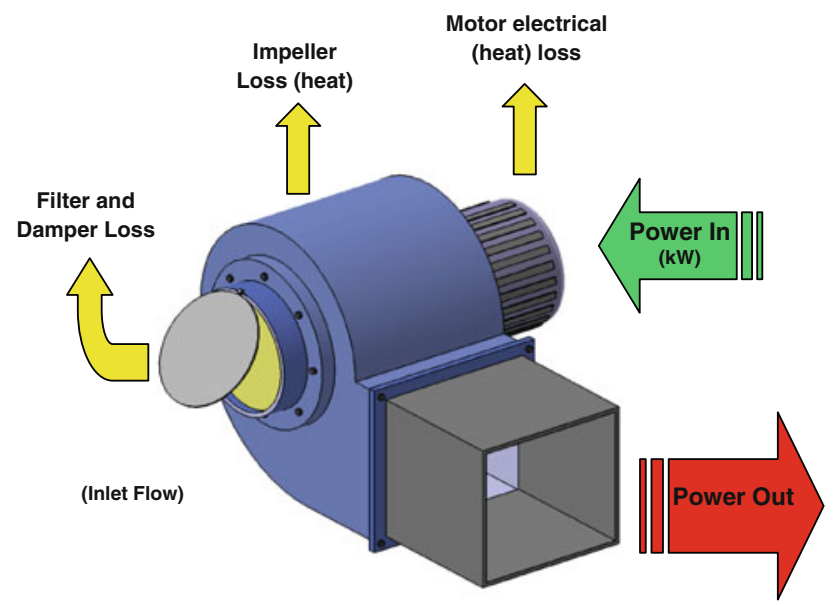

Fig. 2 Losses from a fan system with a direct drive electric motor

best solution in many applications such as agricultural buildings (Teitel et al. 2008) to energy saving and reduction of energy losses (Kaya et al. 2008). In addition, among all of the successful methods and strategies managers have for minimizing the energy costs is the use of VSDs (Tolvanen 2008).

In this study, the main sources of energy loss in fans are theoretically and experimentally discussed, and the saving energy and related cost when using electrical VSD instead of common pulley and belt system are measured in the experiment by appropriate equations and statistics. The research work commenced on March 2010 and continued until November 2010 at the fluid mechanics laboratory, Science and Research Branch, Islamic Azad University.

\section{Materials and methods}

The experiment has operated on a centrifugal fan and variable speed between 500 and 1,500 rpm and pulley and belt drive in different flow rates using obstacle on the inlet channel. Power was measured in different speeds by a wattmeter with accuracy of $5 \mathrm{~W}$ and speed was measured by an optical tachometer with 1-rpm accuracy. To control the temperature a PT100 electrical-resistance thermometer was used. All the measurement tools were calibrated; a stroboscope was used for the optical tachometer and an ohmmeter for the electrical-resistance thermometer. The inlet and outlet temperatures during the experiment were kept constant and equal to $20 \pm 1^{\circ} \mathrm{C}$. The experiment was operated in three states: fully closed without flow rate, $40 \%$ of maximum flow rate and maximum flow rate. Maximum flow rate is state which can be reached in all motor speeds.

\section{Results and discussion}

In this section, the experimental results of replacing mechanical drive (pulley and belt) by electrical variable speed drive for a centrifugal fan are presented. Power of a centrifugal fan with variable rpm (500-1,500 rpm) with pulley and belt drive and VSD was measured in different speeds by a wattmeter. This procedure was repeated in different flow rates using obstacle on the inlet channel. The results are shown in Figs. 3, 4, 5, and 6.

It can be seen that in all the experiment conditions, there was an upward trend in the electrical consumption of 


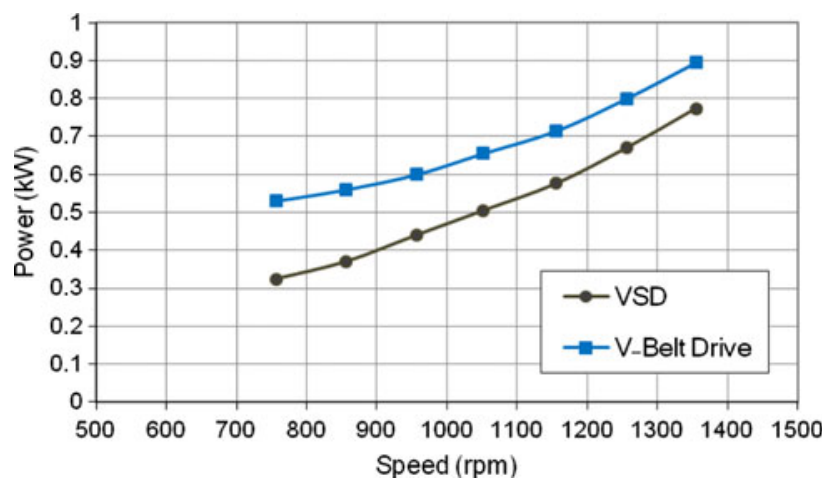

Fig. 3 Comparison of consumption power in pulley and belt drive with electrical drive (fully closed, without flow rate)

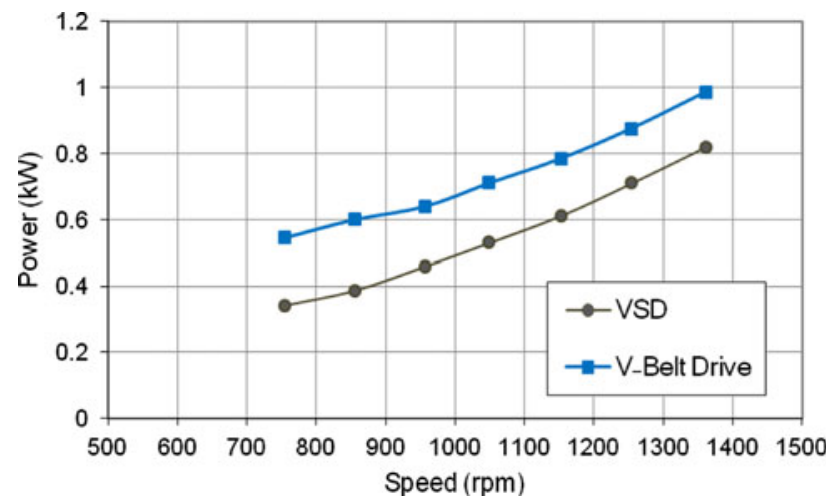

Fig. 4 Comparison of consumption power in pulley and belt drive with electrical drive ( $40 \%$ of maximum flow rate)

centrifugal fan and a gradual decline in energy savings as the speed rises. So, in higher motor speeds the energy saving is falling down.

There are some equations to estimate annual energy savings using VSD (Abdelaziz et al. 2010). Annual energy consumption of electrical motor for the centrifugal fan in the experiment without using VSD can be determined by the following equation:

$\mathrm{AEC}_{\mathrm{BAU}}$

$=\underline{\text { Motor power } \times \text { Number of motors } \times \text { Operating hours per year }}$ Motor efficiency

where $\mathrm{AEC}_{\mathrm{BAU}}=$ Annual energy consumption without VSD, $\left(\frac{\mathrm{kWh}}{\text { year }}\right)$.

Annual energy consumption of the centrifugal fan electrical motor when using VSD can be calculated as below:

$\mathrm{AEC}_{\mathrm{NP}}=$ Annual energy consumption without VSD

$$
\times(1-\text { Speed reduction ratio })^{2}
$$

where $\mathrm{AEC}_{\mathrm{NP}}=$ Annual energy consumption with VSD, $\left(\frac{\mathrm{kWh}}{\text { year }}\right)$.

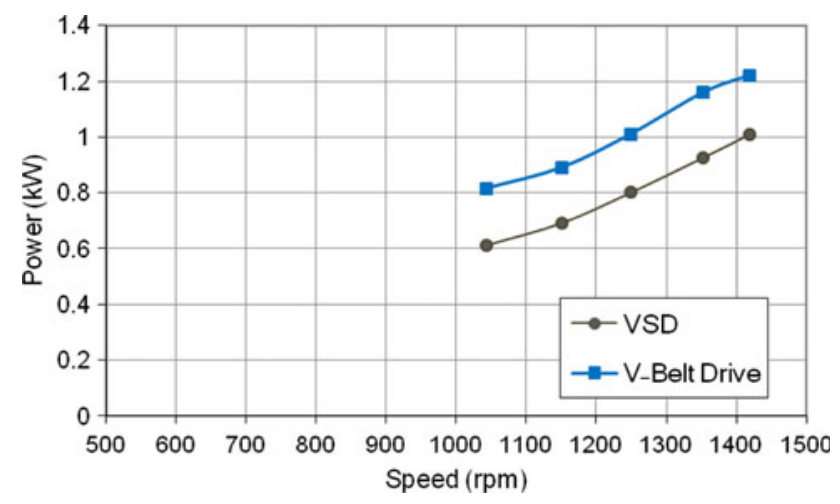

Fig. 5 Comparison of consumption power in pulley and belt drive with electrical drive (maximum flow rate)

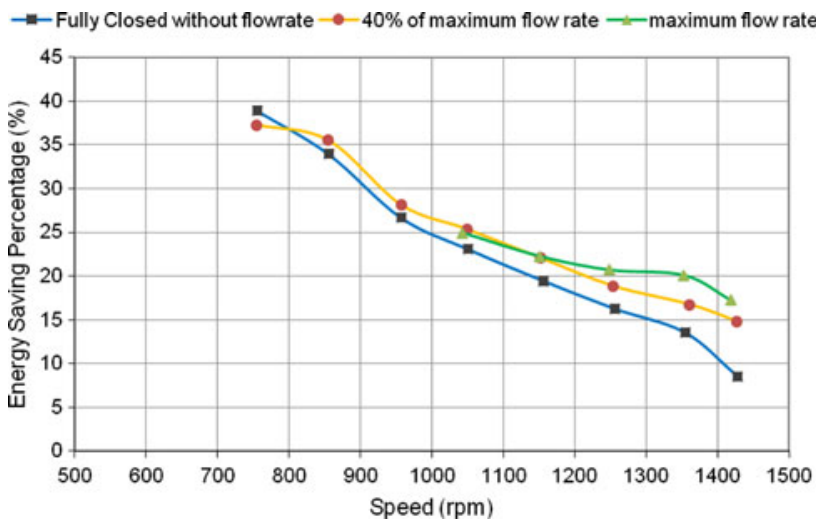

Fig. 6 Losses reduction rate in relation to speed of electrical drive to mechanical drive (all three states)

And finally, the annual energy saving when using VSD equals the difference of above equations:

$\mathrm{AEC}_{\mathrm{VSD}}=\mathrm{AEC}_{\mathrm{BAU}}-\mathrm{AEC}_{\mathrm{NP}}$

where $\mathrm{AEC}_{\mathrm{VSD}}=$ Annual energy saving when using VSD, $\left(\frac{\mathrm{kWh}}{\text { year }}\right)$.

In addition, the energy cost saving when using VSD in the centrifugal fan can be estimated from following equation:

$\mathrm{ABS}_{\mathrm{VSD}}=\mathrm{AEC}_{\mathrm{VSD}} \times \mathrm{UEP}$

where $\mathrm{ABS}_{\mathrm{VSD}}=$ Annual bill saving of VSD, $\left(\frac{\text { Rials }}{\text { year }}\right)$,

$\mathrm{UEP}=$ Unit energy price, $\left(\frac{\mathrm{Rials}}{\mathrm{kWh}}\right)$.

The results from the data achieved in the experiment and using above equation are shown in Figs. 7, 8, 9, and 10 .

From the figures above, the reduction of energy loss can be shown in Table 1.

As it seems in the figures above, there is an upward trend in annual energy consumption when using VSD by increase in reduction speed ratio. Also, using VSD in the centrifugal fan used in the experiment, the energy cost can 


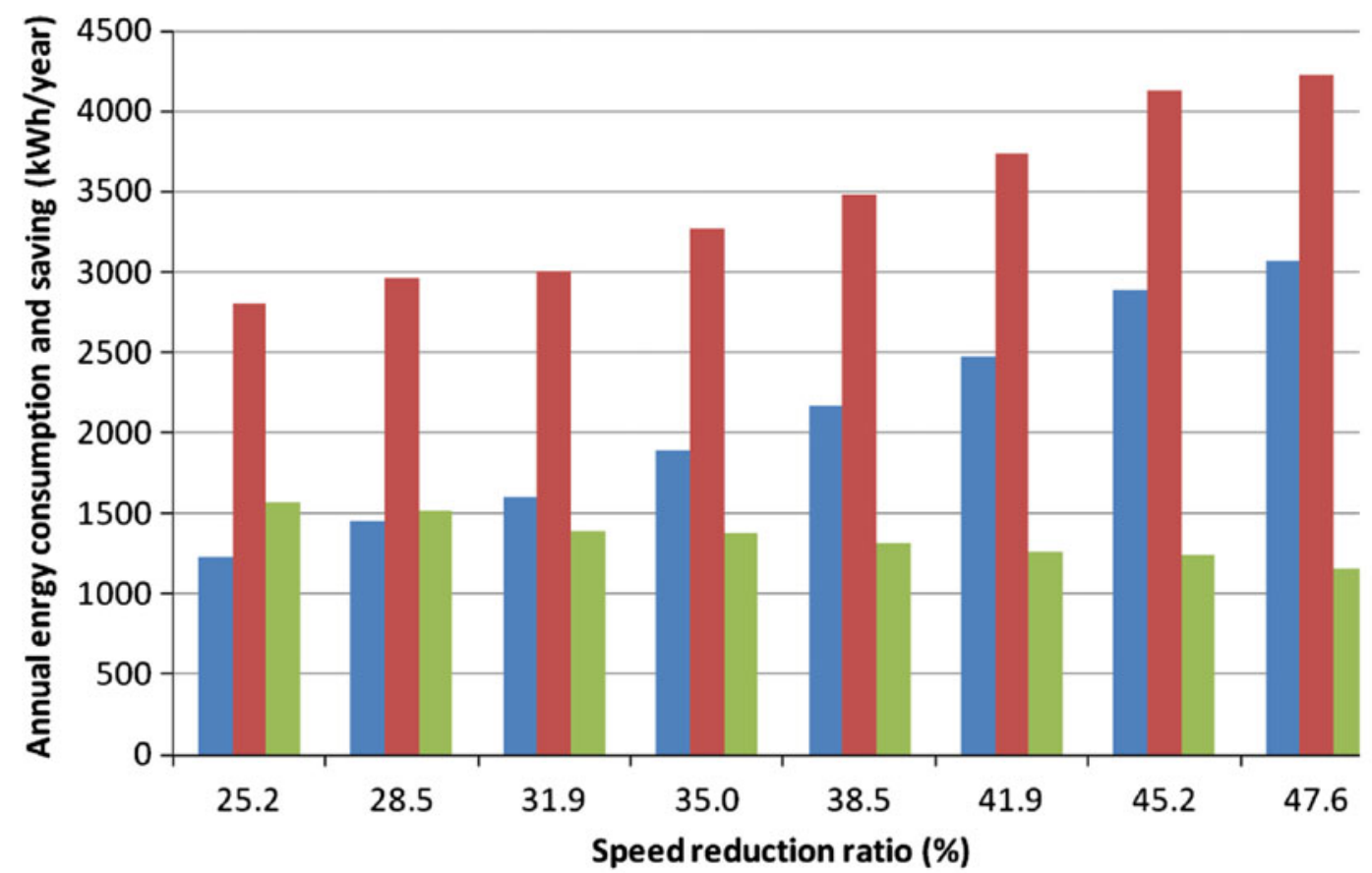

Annual Energy savingusing VSD anunual energy consumption without VSD E Annual enrgy consumption when using VSD

Fig. 7 The annual energy consumption without VSD and with VSD and the annual energy saving when using VSD in fully closed without flow rate state

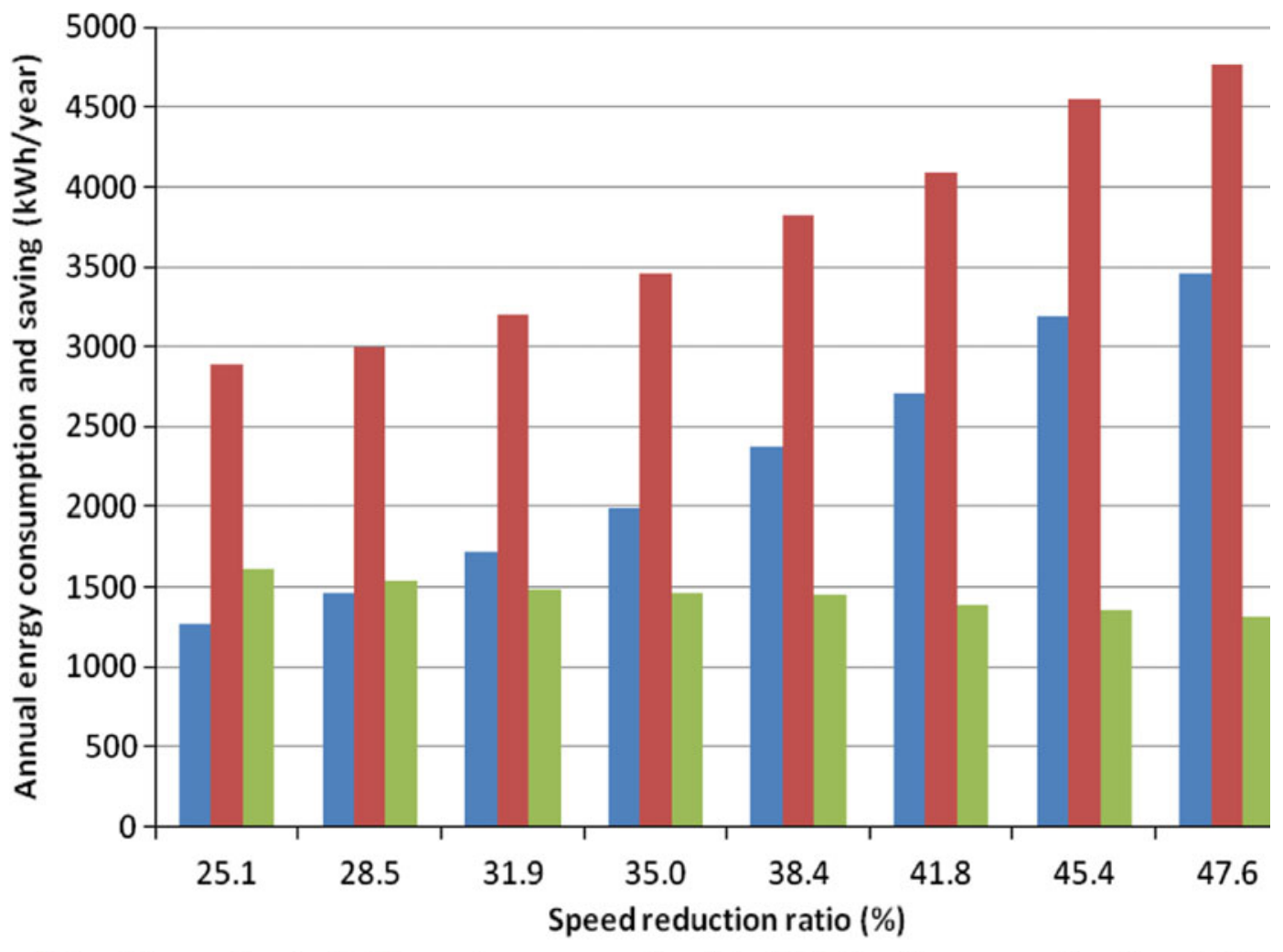

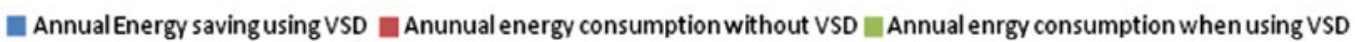

Fig. 8 The annual energy consumption without VSD and with VSD and the annual energy saving when using VSD in $40 \%$ of maximum flow rate 


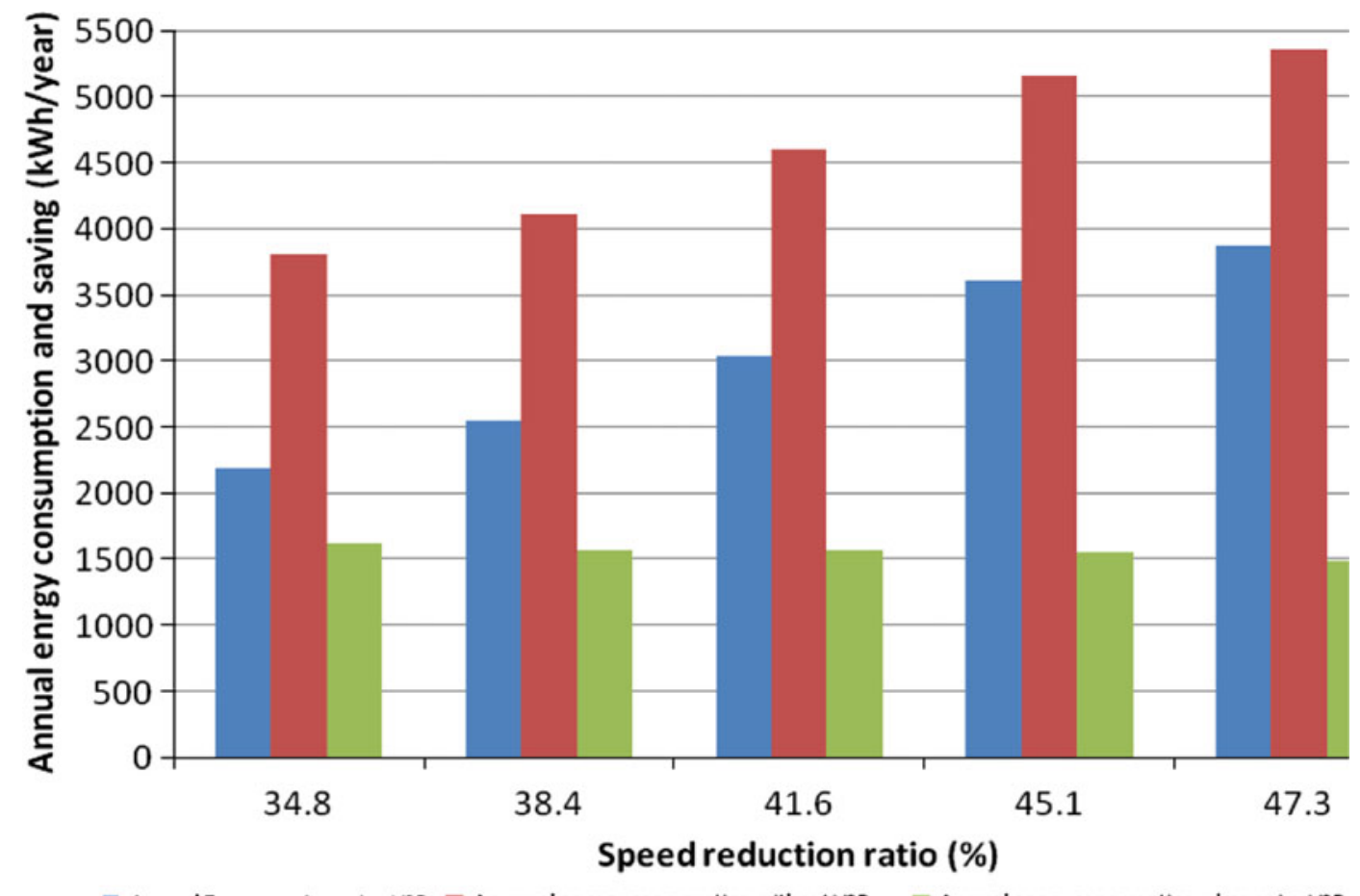

Annual Energv saving using VSD Anunual energv consumption without VSD Annual enrgv consumption when using VSD

Fig. 9 The annual energy consumption without VSD and with VSD and the annual energy saving when using VSD in maximum flow rate

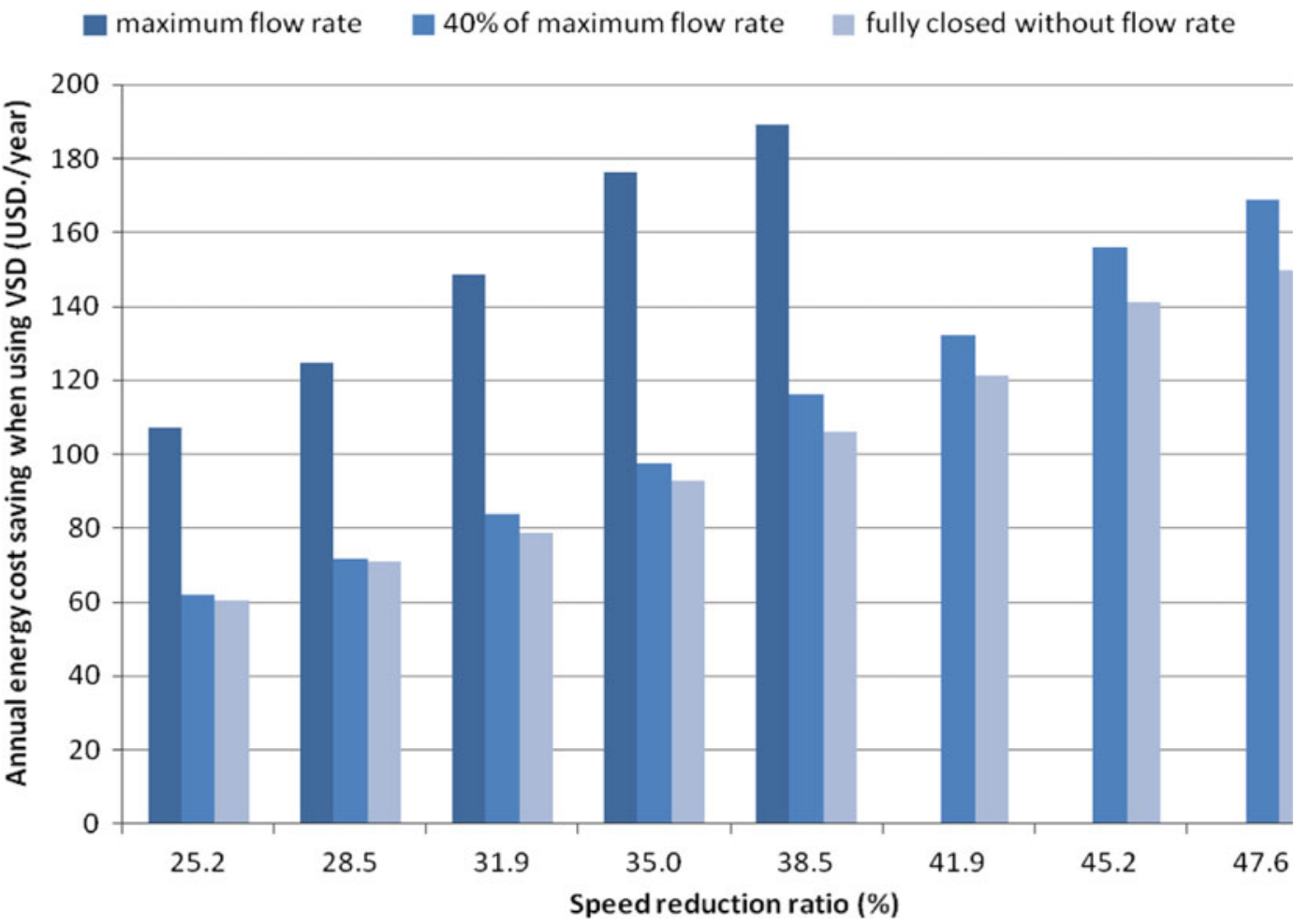

Fig. 10 The annual energy cost saving when using VSD in all states 
Table 1 Reduction of energy loss in fan

\begin{tabular}{llll}
\hline Fan system & $\begin{array}{l}\text { Energy } \\
\text { saving }(\%)\end{array}$ & $\begin{array}{l}\text { Annual energy saving } \\
\text { when using VSD } \\
\text { (kWh/Year) }\end{array}$ & $\begin{array}{l}\text { Annual energy cost } \\
\text { saving when using VSD } \\
\text { (Rials/Year) }\end{array}$ \\
\hline Electrical VSD (fully closed without flow rate) & $8.5-38.5$ & Up to 3,063 & Up to 1,225,400 \\
Electrical VSD (40 \% of maximum flow rate) & $14.5-37$ & Up to 3,453 & Up to 1,381,130 \\
Electrical VSD (maximum flow rate) & $17-25$ & Up to 3,868 & Up to 1,547,420 \\
\hline
\end{tabular}

be saved up to 150 USD./year for fully closed without flow rate, 169 USD./year for $40 \%$ of maximum flow rate and 189 USD./year for maximum flow rate in Iran where average unit price of electrical energy is 0.049 USD./kWh.

\section{Conclusion}

Nowadays, saving energy and its optimum use is highly regarded. Fans have many applications in industry, commercial buildings, hospitals, etc. and they consume considerable amount of energy. Therefore, inappropriate usage and service of fan may cause excessive energy losses. In this study, energy loss factors in fans were discussed and it was shown that proper selection, installation and service (in damper, filter, lubrication, etc.) can reduce energy loss. For example appropriate selection of filter and damper causes reduction in energy losses by up to 40 or $50 \%$, respectively. Also, by replacement of mechanical pulley and belt drive with an electrical VSD, reduction of energy loss up to $38.5 \%$ according to the different flow rates was achieved (Table 1). Of course it can save considerable amount of energy and energy cost that may be used in other industrial applications.

In general, energy loss sources in fan system can be due to incorrect selection of electrical motor and its low efficiency, incorrect selection of fan according to its function, inappropriate fan rpm (i.e., high or low), incorrect selection of fan vanes according to the application, inappropriate lubrication and incorrect selection of oil and grease, incorrect selection of fan bearing, incorrect installation and selection of damper, not replacing the fan filter on regular time, not installed required inlet and outlet channels, using a single fan instead of multiple parallel fans arrangement (Using multiple fans imply lower energy loss compared to a big fan operating in the same condition.), fan unbalancing, incorrect installation of fan, using mechanical drive instead of electrical VSD.

Acknowledgments The authors would like to thank Islamic Azad University; Science and Research Branch for their cooperation to do the experiment in Department of Mechanical Engineering's Fluid Mechanics Laboratory.

\section{References}

Abdelaziz EA, Saidur R, Mekhilef S (2010) A review on energy saving strategies in industrial sector. Elsevier Ltd., Amsterdam, pp 150-168

Action Energy, Good Practice Guide GPG383 (2004) Energy savings in fan and fan systems, HMSO, Norwich, 1-6 Anon, Ninth Malaysian Plane 2006-2010 (2006)

AMCA Publication 202, Troubleshooting and AMCA Publication 410, (2004) Recommended safety practices for users and installers of industrial and commercial fans, pp 39-42

AMCA Standard 300-05 (2004) Reverberant Room Method for Sound Testing of Fans, 43-AMCA Standard 204. Balance Quality and Vibration Levels for Fans, pp 34-38

Andrews I, Biggs C, Cowell P, Davis I, Hopkins D, Lockwood G, Mulholland R (2006) Fan Application Guide-TM42. CIBSE, London, pp 1-6

Beggs C (2002) Energy management, supply and conservation. Butterworth-Heinemann, Elsevier Ltd., Amsterdam, pp 200-204

Belimo Worldwide (2008) Fan optimizer, less energy, more comfort, pp 1-2

Bleier FP (1998) Fan handbook selection, application \& design, chapt. 4. McGraw-Hill Book Co, USA, pp 12-16

Building LEO (2005) Energy performance of LEO building, ministry of energy, post. Telecommunication, Putrajaya, pp 1-2

Dudley DF (1984) Theory and practice of lubrication for engineers. Wiley-Interscience publication, Oxford, pp 295-298

EC (2007) in Malaysia, Energy Commission, Malaysia, pp 4-12

Jayamaha L (2006) Energy-efficient building systems. McGraw Hill, USA

Kaya D, Alptekin YE, Suleyman YK, Fatma CK, Salih EA, Cenk C (2008) Energy efficiency in pumps. Energy Convers Manag 49:1662-1673

Lönnberg M (2007) Variable speed drives for energy savings in hospitals. World Pumps 494:20-24

Matsuki Mikio (1998) Norio Tanaka, Energy Saving System for Air Conditioning of Clean Room for Semiconductor Factory. Oki Tech 63:49-52

Reese H, Carolus T, Kato C (2007) Numerical prediction of the aeroacoustic sound sources in a low pressure axial fan with inflow distortion. Fan Noise, Lyon, pp 1-12

Mechnical Equipment Supply Company Inc. (2005) Inlet Vane Damper, Newjersey, USA, pp 2-11

Marais J (2009) Increased energy savings through a compressed air leakage documentation system. ICUE, SA, pp 1-6

Massarrat M (2004) Iran's energy policy: current dilemmas and perspective for a sustainable energy policy. Int J Environ Sci Technol 1(3):233-245

Mecrow BC, Jack AG (2008) Efficiency trends in electric machines and drives. Energy Policy 36:4336-4341

Radgen P (2006) Potential of compressed air energy efficiency Part-3, CAS EE-Making Enhancement Happen. Enersize Ltd., Finland, pp 8-12 
Ragden P (2001) Market study for improving energy efficiency for fans. Fraunhofer-Informationzentrum Ruam and Bau IRG, Stuttgart, pp 1-6

Rockwell Automation (2007) Energy savings with variable frequency drives, Publication 7000-AR002C-EN-P, Rockwell Automation Inc. USA, pp 1-3

Saidur R (2009) Energy consumption, energy savings and emission analysis in Malaysian office buildings. Elsevier Ltd., Amsterdam, pp 4104-4113

Saidur R, Rahim NA, Hasanuzzaman M (2009) A review on compressed-air energy use and energy savings. Elsevier Ltd., Amsterdam, pp 1135-1153
SKF (1992) SKF General Catalogue, SKF publication, pp 6-9

Teitel M, Zhao ALY, Barak M, Eli Bar-lev, Shmuel D (2008) Energy saving in agricultural buildings through fan motor control by variable-frequency drives. Energy Build 40:953-960

Tolvanen J (2008) Saving energy with variable speed drives. World Pumps, pp 32-33

Xu T, Lan C, Jeng M (2006) Performance of large fan-filter units for cleanroom applications. Elsevier, Amsterdam, pp 2299-2304 